\title{
RESULTS OF RESEARCH OF COMBINE HARVESTER CUTTERBAR
}

\author{
Kateryna Sheheda ${ }^{1}$, Oleksandr Shokarev ${ }^{1}$, Serhii Kiurchev ${ }^{1}$, \\ Mykola Danchenko', Lyudmyla Mykhailova ${ }^{2}$ \\ ${ }^{1}$ Tavria State Agrotechnological University, Ukraine; \\ ${ }^{2}$ State Agrarian and Engineering University in Podillia, Ukraine \\ alexandr.shokarev@gmail.com, dakgps@pdatu.edu.ua
}

\begin{abstract}
The new combine harvester technology for grain crops also includes combing the plants at the root. However, harvesting of the combed stalks is still a major constraint on the widespread use of the new harvesting technology. The segmented tine cutter with reciprocating blade movement is the most compact and technologically reliable for cutting the combed stalks. A conveyor mechanism designed as an endless chain loop with rakes attached to it is used to clean the cutting area. Rakes are positioned above the cutterbar parallel to the plane of the segments, on which the cut stalks are transported to the exhaust window zone. However, using the small-sized above-mentioned cutterbar raises the problem of balancing transverse vibrations and rake clearing in the windrow formation zone. The geometric parameters of a cutting unit based on an endless chain with an active windrower are grounded in the article. A system of equations for determining the range of possible impact point values on the surface of the reflecting roller is obtained. This is used in modeling the interaction of the stalk with the surface of the rollers. This system of equations also makes it possible to determine the maximum height that the stalk can reach in its turning. This is necessary to substantiate the height of the rollers. When studying the mechanical and technological features of interaction between the combed stalks and the working elements of the cutting unit, the following tasks were solved: the chosen scheme of stalk transport forms and places the swath between the working organs of the combine harvester; as a result of kinematic analysis of the transporting mechanism it has been determined that at the place of rake turning there are good conditions for cleaning this mechanism from the stalks and forming a swath. A physical model of the interaction of the stems with the surface of the windrower in the form of two reflecting rollers that form a single unit with the sprockets of the conveying mechanism has been developed. Using such unit would reduce the vibration of the cutter and improve the quality of cleaning the rake in the windrow forming zone.
\end{abstract}

Keywords: combing plants, cutting unit, windrower.

\section{Introduction}

Harvesting by the method of combing the plants at the root is one of the promising directions of combine technology of grain crops harvesting. This method makes it possible to increase the productivity of combine harvesters many times with a significant reduction in their energy and metal consumption. Grain crops and rice harvesting by combing plants at the root is being carried out by scientists in many countries around the world [1-5]. But to increase the reliability of technological process of harvesting crops, it is necessary to improve the reliability of the working parts of the cutterbar of the combine harvester. Several types of cutterbar are currently known to cut the combed stalks in front of the harvester across the full working width of the combing unit and place them in the swath, which existing machine complexes are able to pick up and utilise. For example, picking up swathes and baling straw [6;7]. This method of utilization of the non-grain part of the crop is most relevant for rice harvesting, since the stubble residue is sufficient for the mulch layer after harvesting rice by combing plants on the root. A large amount of rice straw in moist soil rots and impairs soil fertility $[4 ; 6-8]$. The segmented cutting unit with reciprocating blade movement is the most compact and technologically reliable for cutting the combed stalks. To clean the cutting area, a conveyor mechanism is used, which is designed as a contour of endless chain with rakes attached to it, positioned above the cutterbar parallel to the plane of the segments (Fig. 1).

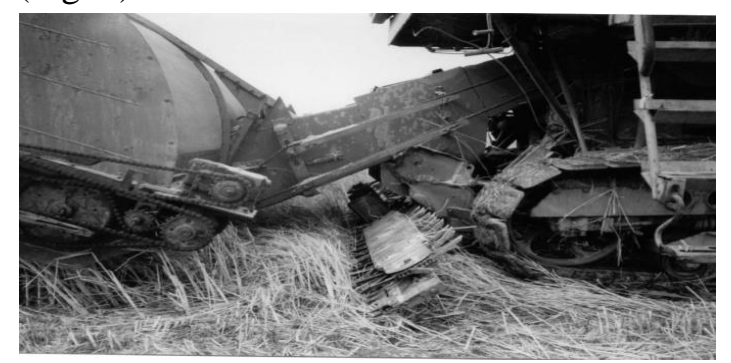

Fig. 1. Segment type cutter with conveyor mechanism 
The transportation mechanism consists of two circuits, each of which moves towards the centre of the unit into the swath forming zone.Reorientation of the cut stalks is ensured by applying lateral blows to them below the center of gravity $[4 ; 7]$.

\section{Materials and methods}

The problem of balancing transverse vibrations arises when using the small cutterbar mentioned above. When the crank of the drive mechanism rotates evenly, the blade and other parts of the cutterbar have directionally variable accelerations. The forces of inertia generated in this process cause dynamic pressure in the mechanisms $[9 ; 10]$. This pressure is transmitted to the entire cutterbar causing shaking and oscillation.

The lateral movement of the cutterbar $\left(\mathrm{S}_{\mathrm{nn}}\right)$ can be determined from the equation:

$$
S_{n n}=\frac{\pi}{4} \cdot \frac{m_{u}}{m_{p n}} \cdot \sqrt{\left(2 S-B_{o}-B_{1}\right)\left(B_{o}+B_{1}\right)},
$$

where $m_{H}$-blade weight;

$m_{p n}$ - cutting unit weight;

$S$ - blade stroke;

$B_{0}-$ segment top edge width;

$B_{1}-$ width of the contradicting part of the finger.

In the presented cutting device (Fig.1) the blade weight $m_{H}$ is $29 \mathrm{~kg}$, cutting unit weight $m_{p n}$ is 90 $\mathrm{kg}$, blade stroke $S$ is $76 \mathrm{~mm}$, segment top edge width $\theta_{o}$ is $10 \mathrm{~mm}$ and the width of the contradicting part of the finger $B_{1}$ is $16 \mathrm{~mm}$ [7].

Calculations show that transverse vibration amplitude of a serial cutterbar for direct harvesting is $0.8 \mathrm{~mm}$, whereas for a combinatorial cutterbar it is by one order of magnitude higher - $10 \mathrm{~mm}$ [7]. A transverse vibration amplitude of $10 \mathrm{~mm}$ increases the likelihood of stalk slippage considerably by increasing the transverse bending of the stalks, which has a negative effect on the loss of the non-grain part of the crop.

By determining the value of the blade inertial force, it is possible to solve a number of problems relating to the reduction of vibrations in the device, calculation of individual parts for strength, determination of the pressure in the kinematic couples [11]. The value of the forces of inertia gives an indication of the energy required to overcome their resistance.

The power required for this purpose is determined by the formula:

$$
N=\frac{m_{u} \cdot \omega^{3}}{4 \pi} \cdot\left(2 S-B_{o}-\beta_{1}\right) \cdot\left(B_{o}+B_{1}\right),
$$

where $\omega$ - cyclic frequency of the blade.

For the cutterbar (Fig. 1) the cyclic frequency of the blade vibrations is $76 \mathrm{c}^{-1}$ [7]. It is therefore necessary to expend $1.1 \mathrm{~kW}$ of drive power on this cutterbar to overcome the resistance of the inertial forces.

From the above, the following conclusions can be drawn: in order to reduce the transverse vibration amplitude of the cutting unit, it is necessary to balance the forces of inertia by using a cutterbar based on an endless chain. The proposed cutting device (Fig. 2) contains two cutting units, each of which consists of an endless traction element 1 on the lower plane with fixed segment knives 3, on the upper plane is fixed the conveying rake 2 . Segment knives 3 rotate without vibration over the counteracting fingers 4 . Reflective rollers 6 of the active windrower, as well as working branches of the cutting units are moving in the opposite direction to the throwing window, where the divider 5 is installed.

The cutting unit functions as follows. The plants are cut by the segment knives 3 (Fig. 2) in interaction with the counter cutting fingers 4 . At the moment of cutting the rake 2 interacts with the plants on its side and reorients them so that they end up on the upper surface of the rake 2 . The cut crop is moved onto the rake 2 over the cutting area until it reaches the swath formation point, thus the cutting area is constantly cleared of cut stalks. The rake 2 is cleared and the swath is formed by a sudden increase in the linear speed as the rake turns. At this time, the cut stalks interact with the surface of deflecting 
rollers 6 of the active windrower and change the direction of movement to the desired area of space the throwing window area. This improves the passage of the cut crop, completely clears the cutting area around the exit window and forms a swath. The plants approaching the cutterbar centrally are fed by the divider 5 to the cutterbar. This allows all plants to be cut without any skips.

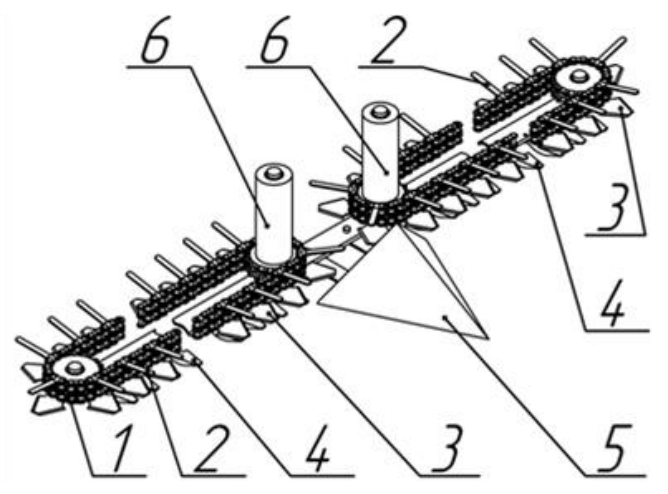

Fig. 2. Cutterbar of the combing harvester: 1 - endless traction element; 2 - transporting rake; 3 - segment knives; 4 - counter cutting fingers; 5 - divider; 6 - deflecting rollers

Consider the pattern of interaction between the stalk and the surface of the reflection roller (Fig. 3), which is constructed on the basis of the scheme of the proposed cutting unit (Fig. 2).

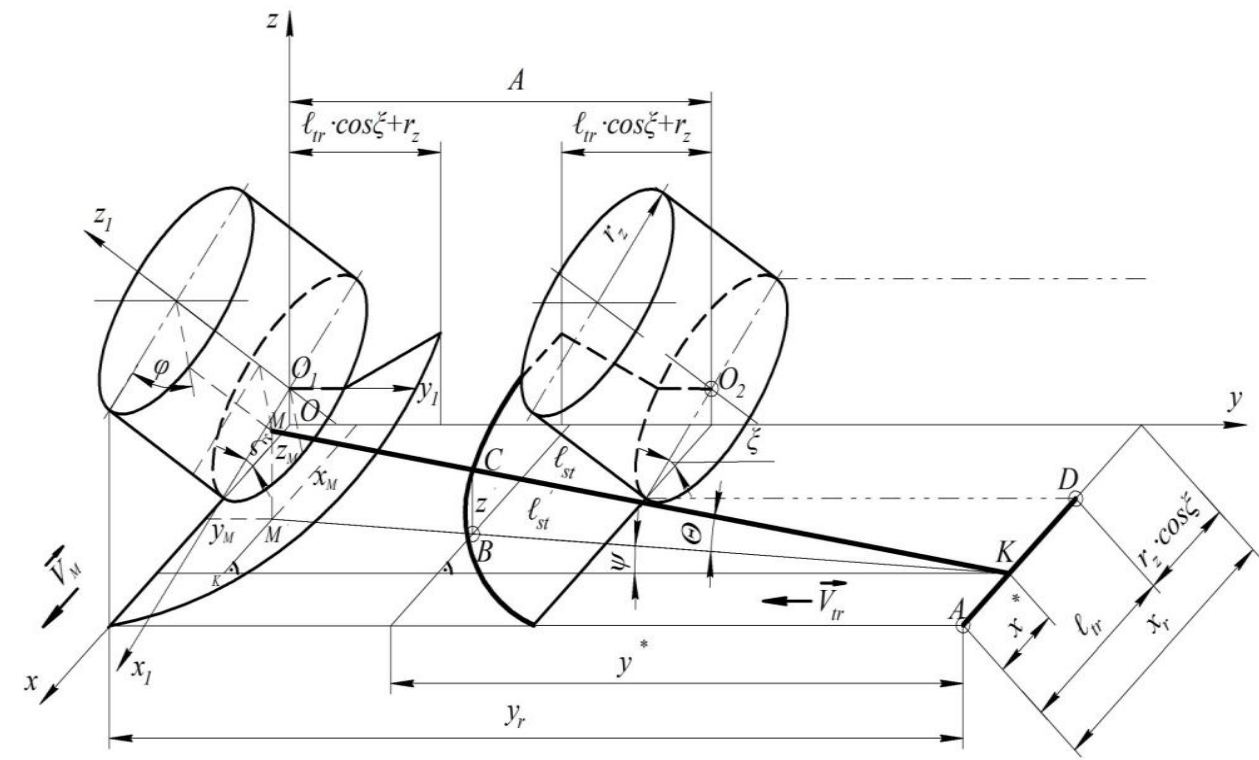

Fig. 3. Scheme of interaction of the stalk with the cylindrical surface of the reflection roller

For this purpose, introduce the following two coordinate systems: $O X Y Z$ - associated with the combine harvester, where the $O X$ axis is directed in the direction of the combine harvester movement parallel to the soil, the $O Y$ axis is perpendicular to the direction of the combine harvester movement and parallel to the soil, $O Z$ axis - vertically upwards (perpendicular to soil surface) and coordinate system $O_{1} x_{1} y_{1} z_{1}-$ connected to the shaft, where the $O_{1} x_{1}$ axis is in the direction of the combine movement and angled $\xi$ to the $O X$ axis, the $O_{1} y_{1}$ axis is parallel to the $O Y$ axis, but $O_{1} z_{1}$ is directed along the reflecting roll axis $\left(O_{1} x_{1} z_{1} O X Z\right)$.

The value $X^{*}$ determinesthe position of the edge of the stalk on the transporter rake, and the same stalk in the $O X Y$ plane with the $O Y$ axis forms an angle $\psi$ (Fig. 3). The value of $X^{*}$ can vary within the range from 0 to $l_{t r}$ (the lengthof thetransporting rake), however, from Fig.4 it can be seen that the range of possible values of $X^{*}$, when thestalk is moving without clamping, is actually reduced to the interval from $\left[0 ; l_{t r} \cdot \cos ^{2} \xi\right]$. The value of thechosen scheme (Fig. 4) is determined by the expression: 


$$
\psi_{\max }=90^{\circ}-\beta=90^{\circ}-\operatorname{arctg} \frac{l_{t r} \cdot \cos \xi \cdot \sin \xi}{l_{t r} \cdot \cos ^{2} \xi-X^{*}} .
$$

Thus, the problem of determining the range of possible impact point values $M$ on the surface of the reflecting roller is reduced to the problem of considering a function of two variables $X^{*}$ and $\psi$.

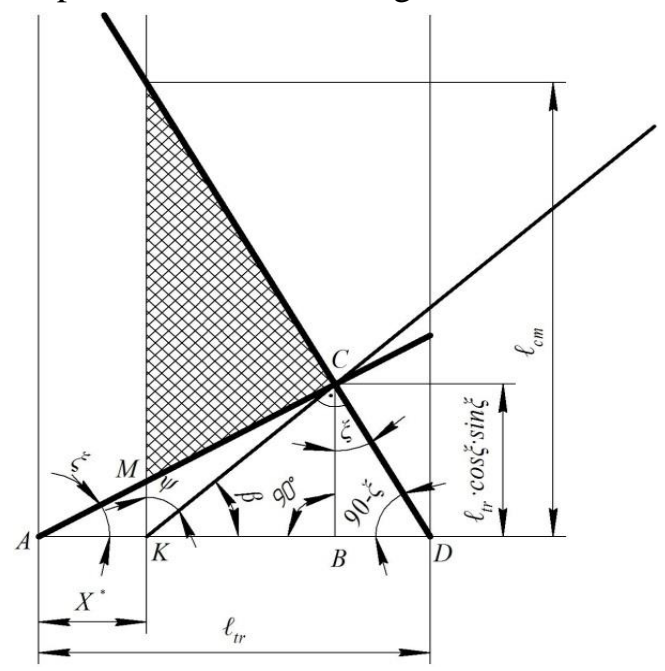

Fig. 4. Angle $\psi$ value calculation diagram

Initial data in this task are: stalk length $\left(l_{s t}\right)$, position of stalk center of mass $\left(l_{c m}\right)$, distance between rotating reflecting surfaces $(A)$, inclination angle between $O X$ and $O_{1} x_{1}$ axes $(\xi)$, length of transporting rake $\left(l_{t r}\right)$. Consider that the rotating surface has the form of a cylinder with radius $r_{r}=r_{z}$.

Considering the influence of all the above quantities on the impact point position $M$ in the $O X Y Z$ coordinate system and using the diagram (Fig. 3) for the calculation, we derived the following system of equations:

$$
\left\{\begin{array}{l}
X_{M}=l_{t r}+r_{z} \cdot \cos \varepsilon-X^{*}-l_{s t} \cdot \cos \theta \cdot \sin \psi \\
Y_{M}=Y_{r}-l_{s t} \cdot \cos \theta \cdot \cos \psi \\
Z_{M}=l_{s t} \cdot \sin \theta
\end{array} .\right.
$$

The projections of the impact point $M$ in the $O X Y Z$ coordinate system can also be determined from the calculation diagram shown in Fig. 5.

In this case we obtain the following system of equations:

$$
\left\{\begin{array}{l}
X_{M}=x_{1} \cdot \cos \xi+z_{1} \cdot \sin \xi \\
Z_{M}=r_{z} \cdot \sin \xi+z_{1} \cdot \cos \xi-x_{1} \cdot \sin \xi, \\
Y_{M}=y_{1}=\sqrt{r_{z}^{2}-x_{1}^{2}}
\end{array}\right.
$$

where $\quad x_{1} y_{1}, z_{1}$-coordinates of the impact point $M$ in the $O_{1} x_{1} y_{1} z_{1}$ coordinate system.

Considering the relationship between the angular parameters of the stem movement $\theta$ and $\psi$, using Fig. 3, the following relationship was determined between them:

$$
\theta=\arctan (\operatorname{tg} \xi \cdot \sin \psi) \text {. }
$$

The considered scheme of stalk interaction with the reflection roller surface of the conveying mechanism of the cutting unit on the endless traction element confirmed the presented hypothesis. The hypothesis suggests the use of a cutting unit containing two cutterbars in the form of endless traction elements with segments and rakes. The cutting unit differs by the fact that in order to increase the 
reliability of the technological process, an active windrower is installed in the throw window area in the form of two reflecting rollers, which make a single unit with the sprockets of the cutterbar drive.

\section{Research and discussion}

The resulting system of equations (4) and equation (6) allow the position of the impact point $M$ on the surface of the reflecting roll in any of the presented coordinate systems to be determined with fixed values of $X^{*}$ and $\psi$.

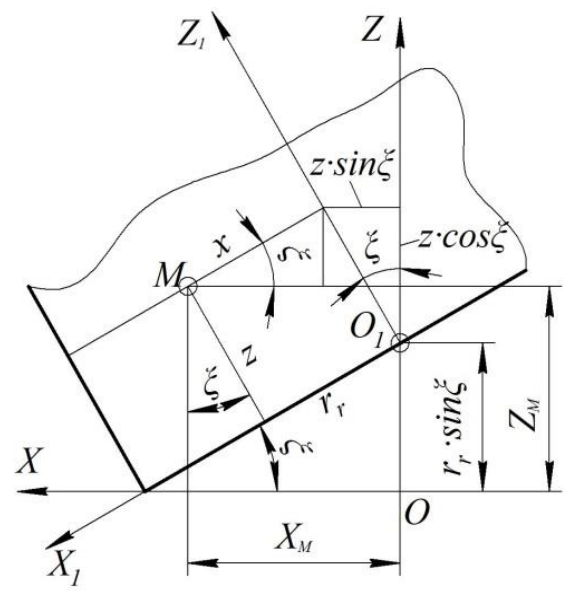

Fig. 5. Z-value calculation diagram

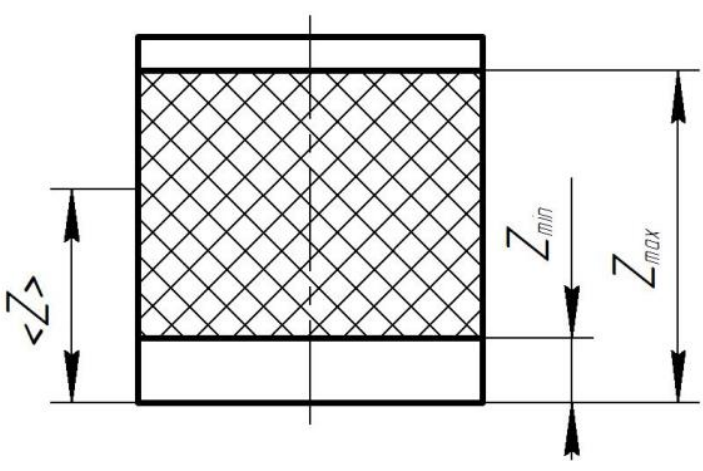

Fig. 6. Justification scheme for roller heights

Determining the position of the stalk edge on the transporting rake $X^{*}$ and changing the angle value $\psi$ from 0 to $\psi_{\max }$, using the system of equations (4)-(6), we obtained an array of all possible coordinates of the impact point $M$ in the coordinate systems $O X Y Z$ and $O_{1} x_{1} y_{1} z_{1}$. Since the value $X^{*}$ is a random quantity in real conditions of the stalk motion, the position of the point $M$ is also random.

Statistical processing of the obtained data sets was done. In particular, in $O_{1} x_{1} y_{1} z_{1}$ coordinate system, the area of possible values of $z_{1}$ coordinate is in the interval from $z_{\min }=6.2 \mathrm{~cm}$ to $z_{\max }=31.5 \mathrm{~cm}$ with $\langle z\rangle=20.2 \mathrm{~cm}, \sigma_{z}=6.0 \mathrm{~cm}$ (Fig.6).

The value of the angular coordinate $\mathrm{K}$ in coordinate system $O_{1} x_{1} y_{1} z_{1}$ can vary from $\varphi_{\min }=7^{\circ}$ to $\varphi_{\max }=150^{\circ}$ at $\langle\varphi\rangle=85^{\circ}, \sigma_{\varphi}=35^{\circ}$. The use of the resulting system of equations allows us, firstly, to determine the range of possible values of the impact point $M$ on the surface of the reflecting roller. This is then used to simulate the interaction of the stalks with the surface of the reflection rollers.

Secondly, it makes it possible to determine the maximum height $Z_{\max }$ that the stalk can reach in its headland. This is then used to justify the height of the rollers.

Thirdly, knowing the coordinates $y^{*}, X_{2}-X^{*}$, and the angles $\psi$ and $\theta$ when the stem turns, we can determine the coordinates of the point $M$ in any of the coordinate systems we have chosen.

\section{Conclusions}

In the process of researching mechanical and technological features of interaction of cut stalks with working elements of the cutting device the following problems were solved: the chosen scheme of transporting the incoming mass of stalks forms and encloses a windrow between the combine's movers; as a result of kinematic analysis of the transporting mechanism it was determined that there are favorable conditions for cleaning it from stalks and forming a windrow in the place of turning of the rake. Mathematical modeling of the interaction between the stalks and the reflecting surface of the windrower has determined the conditions that ensure that the direction of movement of the cut stalks into the desired area of space is changed.The rollers are $320 \mathrm{~mm}$ high. The use of such an apparatus will reduce the vibration of the cutting unit and improve the quality of rake cleaning in the windrow formation zone.

A mathematical model of the interaction of the stalks with the surface of the windrower in the form of two reflecting rollers that form a single unit with the sprockets of the transporting mechanism is developed and makes it possible to develop and manufacture a laboratory field device for experimental research. The results of the experimental research of the cutting unit prototype confirmed the correctness 
of the theoretical statements and technological principles of harvesting of combed stalks of grain crops and rice. So, at rice harvesting at the width of the cutting device capturing in $4 \mathrm{~m}$ and the forward speed $-1.5 \mathrm{~m} \cdot \mathrm{s}^{-1}$ the width of the swath was $1.45 \mathrm{~m}$, height of stubble $-160 \mathrm{~mm}$, thus losses of the cut and not included in a swath $-4.1 \%$.

\section{References}

[1] Chegini G., Mirnezami S.V. Experimental comparison of combine performance with two harvesting methods: Stripper header and conventional header. Agricultural Engineering International: CIGR Journal,Vol. 18, Issue 1, 2016, pp. 192-200.

[2] A new harvesting technology and its stripper-featured machine system./Agricultural mechanization in Asia, Africa and Latin America - 1991. Vol. 22.No. 3, pp. 9-14.

[3] Siemens M.C., Hulick D.E. A new grain harvesting system for single-pass grain harvest, biomass collection, crop residue sizing, and grain segregation.TransactionsoftheASABE,Vol. 51, Issue 5, 2008, pp. 1519-1527

[4] Tabor O., Lezhenkin S., Halko O., Vershkov O., Hryhorenko. Mathematical simulation of separating work tool technological process-s-1. E3S Web of Conferences : 22nd International Scientific Conference on Progress of Mechanical Engineering Supported by Information Technology, POLSITA 2019; Czajowice; Poland; 19 September 2019 до 20 September 2019. Czajowice, 2019. - Vol. 132, № 01025

[5] Buryanov A., Chervyakov I. Using combines for cleaning grain crops by non-traditional technologies. INMATEH - AgriculturalEngineering,Vol. 59, Issue 3, 2019, pp. 27-32.

[6] Xie W., Li X., Fang Z., Quan W., Luo H., Wu M. Design of compound machine for rice straw collecting and continuous baling. NongyeGongchengXuebao/Transactions of the Chinese Society of Agricultural EngineeringVol. 35, Issue 11, 2019, pp. 19-25.

[7] Shokarev O.M. Justification of technological scheme and main parameters of the cutting device of rice harvesters of combing type. Ph.D. thesis abstract.) Luhansk: LSAU, 2002. (In Ukrainian)

[8] Korchak M., Yermakov S., Maisus V. etc. Problems of field contamination when growing energy corn as monoculture. Proceedings of 6 th International Conference - Renewable Energy Sources, vol. 154, E3S Web of Conferences. 2020. pp. 01009 DOI: 10.1051/e3sconf/202015401009.

[9] Kiurchev S., Verkholantseva V., Kiurcheva L., Dumanskyi O. Physical mathematical modeling of the vibrating conveyor drying process of soybeans/Latvia University of Sciences and Techologies Faculty of Engineering, Jelgava, May 2020, pp. 991 -996

[10] Ivanyshyn V., Yermakov S., Ishchenko T. etc. Calculation algorithm for the dynamic coefficient of vibro-viscosity and other properties of energy willow cuttings movement in terms of their unloading from the tanker. Proceedings of 6 th International Conference - Renewable Energy Sources, vol. 154, E3S Web of Conferences. 2020. pp. 04005.DOI: 10.1051/e3sconf/202015404005

[11] Yermakov S., Hutsol T., Mudryk K. etc. The analysis of stochastic processes in unloading the energy willow cuttings from the hopper. Environment, Technology, Resources. In Proceedings of the 12 th International Scientific and Practical Conference, 2019, Rezekne, Latvia, pp. 249-252. DOI: $10.17770 /$ etr2019vol3.4159 